\title{
A scenario analysis of potential long-term impacts of COVID-19 on the Tunisian electricity sector
}

\section{Francesco Gardumi ( $\nabla$ gardumi@kth.se )}

KTH Royal Institute of Technology https://orcid.org/0000-0001-8371-9325

\section{Nesrine Mhiri}

Ecole Nationale d'Ingénieurs de Tunis

\section{Mark Howells}

Loughborough University

\section{Franziska Bock}

Deutsche Gesellschaft für Internationale Zusammenarbeit (GIZ) GmbH

\section{Thameur Necibi}

Institut Tunisien de la Compétitivité et des Etudes Quantitatives

\section{Chiheb Bouden}

Ecole Nationale d'Ingénieurs de Tunis

\section{Case Report}

Keywords: COVID-19, Tunisia, Energy-economy, OSeMOSYS, Input-Output, Open source

Posted Date: April 6th, 2021

DOl: https://doi.org/10.21203/rs.3.rs-336979/v2

License: (c) (1) This work is licensed under a Creative Commons Attribution 4.0 International License. Read Full License

Version of Record: A version of this preprint was published at Energy Strategy Reviews on November 1 st, 2021. See the published version at https://doi.org/10.1016/j.esr.2021.100759. 


\section{Abstract}

The COVID-19 pandemic has affected the economy of Tunisia, like that of many other countries. With electricity consumption dropping, consumption patterns changing, international fuel prices plummeting and uncertainty raging, the pandemic has affected not least the planning of investments in electricity supply. Although the government seems unlikely to revise the decarbonisation targets downwards, questions arise on whether the investments planned before the pandemic are still relevant in the changed global landscape and what effects they may have on the country's economy.

In this study, we analyse post-pandemic scenarios for the electricity supply system of Tunisia with an energyeconomy modelling framework, soft-linking the energy modelling tool OSeMOSYS and an open source InputOutput model. We extract insights on the cost-competitiveness of different - previously planned and new electricity supply solutions and their impacts on job creation and loss in the entire economy. We find that renewable solutions based on solar photovoltaic remain highly competitive with gas-fired generation under different projections of gas prices and that several low-carbon and energy efficiency solutions have high potential for job creation.

\section{Introduction}

The COVID-19 pandemic has had deep effects on the global and national economies, including sharp reductions of international fossil fuel prices and of energy demands. Some of these effects may last beyond the time frame of new waves, due to a slow recovery of national economies. The Organisation for Economic Co-operation and Development, OECD [1], shows that international oil prices have fallen and gone negative in some instances. World Bank projections [2] show they may be still far from recovering two years from now. Other online news discuss the possibility they may never recover [3]. In Tunisia, the ministry in charge of energy matters shows that, under the pandemic, the demand for electricity has sharply decreased, mostly due to reduced industrial and service activity [4]. Gas prices, indexed to international oil prices, followed the downward trend with a delay of nine months [5].

In Tunisia, as elsewhere, there is high uncertainty over the economic recovery and the impacts the pandemic may have on the energy sector. The ambitions for increased energy efficiency and renewable energy share have not changed and there seems to be no intention to revise them downwards. However, the long lock-down and the uncertainty on the future may delay the approval of capacity expansion plans and therefore the achievement of policy objectives. Furthermore, the decrease in gas prices, if persisting, may affect the cost competitiveness of renewables and raise questions about the extent of planned investments for the latter.

At the same time, this crisis may open the ground to reflections on questions of security of supply, especially given the uncertainties linked to future gas prices. This could favour renewables and even lead to an increase in ambitions on their penetration.

At the level of the national economy, the reduction of oil and gas prices may have decreased the share of national budget spent on imports and allowed a re-allocation on to other sectors, like health. Furthermore, it may bear the same positive effects that it seems to bear in other OECD countries with regards to purchasing power of consumers and producer prices of goods and services. However, the relation between fall of oil prices 
and national economy is made complex by several factors, not least the impacts on availability of Foreign Direct Investment (FDI). Significant part of the FDI in the MENA region comes from oil exporting countries, which now suffer a fall in revenues due to dropping oil prices [6]. Therefore, overall, the short- to medium-term economic impact of lower oil and gas prices on the Tunisian economy may be negative. Nevertheless, this potential negative impact may be counterbalanced in the longer range through economy-wide gains in employment related to new energy infrastructure investments, if these bear high employment potential and have high local content.

While predicting the economy-wide impacts of the pandemic under such uncertainties is hard, quantitative models may help the national government and utilities to understand how the cost, competitiveness and economy-wide impacts of various policy and investment choices may change under different potential postCOVID-19 futures.

\subsection{Scope}

In this case study, we analyse potential long-term impacts of the COVID-19 pandemic in Tunisia with an energyeconomy model. We provide insights on two main aspects:

- Whether and how the cost-competitiveness of different technological solutions for meeting future electricity demand may shift, in light of changes of demands and international fuel prices due to the pandemic and in light of potential changes in policy and investment priorities;

- What implications different investment choices in the electricity supply sector may bear to job creation and loss across the entire Tunisian economy.

We extract the insights from a range of scenarios, developed in collaboration with a consortium of local institutions involved in energy research and decision making in Tunisia.

The rest of the paper succinctly presents the Methodology and scenarios (section 2), key results (section 3) and policy-relevant insights (section 4). Further details on the methodology are presented in a series of two papers annexed to the present work.

\section{Methodology And Scenarios}

The analysis is carried out with an energy-economy modelling framework, that soft-links the Open Source energy Modelling System - OSeMOSYS [7] - (for the energy part) and an in-house open source Input-Output (I0) model (for the economy part). The methodology is based on, and extends, work by Howells and Laitner [8] and by Winkler et al. [9]. The IO model provides an indication of economy-wide job loss and creation coefficients associated with investment in electricity supply options and energy efficiency measures, per unit of electricity generated or saved: a job creation coefficient of 0.32 for a certain power plant, for example, suggests that 1 PJ of activity of the power plant in one year leads to the creation of 320 jobs; Similarly, a job loss coefficient of 0.58 indicates that $1 \mathrm{PJ}$ of annual activity is causing a loss of 0.58 jobs. The computation is based on the latest publicly available IO Table of Tunisia of 2015 [10] and on several assumptions related to technoeconomic costs of the electricity supply of efficiency technologies, the average wages, the wage share in value 
added, interest rates of debt and equity and local content of investments. All assumptions are annexed to this paper, together with the IO model calculation sheets. The coefficients, as computed by the IO model, are summarised in Table 1.

Table 1. Estimate of job-gains and job-losses per energy system element, in the base year of the modelling period. A downward facing arrow indicates a decrease of the coefficients over the years. All other coefficients are constant.

\begin{tabular}{|lll|}
\hline Technology* & $\begin{array}{l}\text { Job creation coefficient (1000 jobs / } \\
\text { PJ -year) }\end{array}$ & $\begin{array}{l}\text { Job loss coefficient (1000 jobs / PJ } \\
- \text { year) }\end{array}$ \\
\hline 450 MW new CC & 0.32 & -0.58 \\
\hline $300 \mathrm{MW}$ new GT & 0.40 & -0.82 \\
\hline Onshore wind & 0.58 & -0.43 \\
\hline Offshore wind & 1.20 & -0.87 \\
\hline Wind autoproduction & 0.67 & -0.51 \\
\hline Solar PV utility scale & $0.64 \downarrow$ & $-0.46 \downarrow$ \\
\hline $\begin{array}{l}\text { CSP (concentrating solar } \\
\text { power) }\end{array}$ & $1.30 \downarrow$ & $-1.02 \downarrow$ \\
\hline $\begin{array}{l}\text { Solar autoproduction } \\
\text { Energy Efficiency - }\end{array}$ & $0.71 \downarrow$ & $-0.51 \downarrow$ \\
\hline $\begin{array}{l}\text { Residential } \\
\text { Energy Efficiency - } \\
\text { Commercial }\end{array}$ & 0.41 & -0.26 \\
\hline $\begin{array}{l}\text { Energy Efficiency - } \\
\text { Industrial }\end{array}$ & 0.37 & -0.21 \\
\hline
\end{tabular}

The electricity system model in OSeMOSYS determines the least cost evolution of the electricity supply mix of Tunisia and dynamically computes a rough estimate of overall job gains and losses associated with investments, using the coefficients calculated in the 10 model. The techno-economic assumptions underlying the electricity system optimisation are harmonised with those underlying the 10 model. The structure, development and testing of the framework are discussed in the Methods papers linked to this publication. The framework is developed based on the groundwork by Dhakouani et al. [11] and used locally, for analyses related to the development of the Tunisian energy system [12]. Compared to Dhakouani et al., our work enhances the representation of job losses and gains related to energy investments.

The time domain of the study covers from 2015 (for calibration with latest available 10 data) to 2040 . For the electricity system optimisation, each year is split in 108 time steps ( 7 seasons * 2 day types (weekday and weekend) * 8 parts in one day), to ensure a minimum representation of the time variability of loads and variable renewables. The current and potential electricity supply options are represented in detail in the model and 
synthesised in Figure 1. The scheme is an aggregated representation of the electricity supply system of Tunisia, from the primary energy supply (left) to the final demand (right). The rectangular boxes are current or potential electricity supply technologies / processes, whereas the coloured lines are energy vectors flowing between them. The black lines are calculated numbers of $\mathrm{CO}_{2}$ emissions and jobs lost or created, function of the results of the energy system optimisation.

The database populating the model was developed in collaboration with the local consortium and mostly based on data from the energy utility STEG (Société Tunisienne de l'Electricité et du Gaz) and the National Agency for Energy Management (ANME). It is annexed to this paper and structured so as to help the user reconstruct the model we created. The database is described in detail in the Methods papers linked to this publication.

We look at four fictional but realistic scenarios, including direct short-term consequences of the COVID-19 pandemics, long-term projections of these consequences in the future and policy choices that may derive indirectly from reflections made after the pandemic:

- Constant ambition. It represents a situation where current policies are maintained, in the aftermath of the pandemic. The energy efficiency and renewable share ambitions of the government as per the Tunisian Solar Plan (PST) are not changed, both in terms of targets and in terms of technological choices. The foreseen PST targets are enforced, as lower boundaries of installed capacity of solar PV, onshore wind, Concentrating Solar Power and biomass power plants by 2030 [13]. Energy efficiency measures are deployed in the residential, commercial and industrial sectors starting from 2021, allowing $0.8 \%$ annual reduction of electricity demand as a percentage of the demand in 2015. At the same time, the electricity demand decreased by $6.3 \%$ in 2020 compared to 2019 (according to STEG), but it is projected to fully recover to pre-pandemic levels already in 2021 and increase thereafter. The natural gas prices are expected to fall on average by $35 \%$ within 2020 (according to STEG) and to recover thereafter, reaching and overshooting pre-pandemic projections by 2027 . The evolution of electricity demand and gas prices, major drivers of the model results, is presented in Table 1.

Table 2. Electricity demand and gas price projections. Source: STEG.

\begin{tabular}{|llllllll|}
\hline & 2015 & 2019 & 2020 & 2025 & 2030 & 2035 & 2040 \\
\hline Demand (TWh) & 15.7 & 19.8 & 18.6 & 24.1 & 29.5 & 34.5 & 39.6 \\
\hline Gas price (USD/toe) & 295 & 316 & 205 & 316 & 387 & 406 & 430 \\
\hline
\end{tabular}

- Lower ambition. The COVID-19 emergency and the lockdown cause a temporary shift of priorities and consequent delays in the approval of renewable energy and energy efficiency projects in the pipeline. Therefore it is assessed that the targets of the PST cannot be met by 2030 and the deadline is shifted to 2035. At the same time, interventions to increase energy efficiency in final uses start in 2026, instead of 2021. All other conditions are the same as in the Constant Ambition scenario. 
- Increased ambition. The government decides to continue the trend of decreased reliance on gas imports forcedly started during the pandemic and avoid the risk of backlashes due to potential new increases of international oil and gas prices. To do so, it encourages more significant and rapid investments in lowcarbon electricity supply options and their value chains after the COVID-19 pandemic. It is assumed that the degree of local content of investments in renewable energy technologies and energy efficiency measures increases (from 10-20\% as assumed in the Constant Ambition scenario to $40 \%$ ) and that two new potentially effective technologies are included in the supply mix: offshore wind and grid-connected utility-scale batteries. All other policy targets and external conditions are as in the Constant Ambition scenario.

- Prioritising security of supply. Moving from similar considerations as in the Increased Ambition scenario, after the COVID-19 pandemic the government prioritises investments in energy supply options which may reduce the country's dependence on gas imports. A planned new electricity interconnection with Italy becomes operational in 2027 for imports and in 2031 for exports (data from STEG); in addition, the import of natural gas is capped from 2026 on, meaning that from then on any incremental need for gas is met through import of Liquefied Natural Gas (LNG). The import price of LNG is set according to Pappis et al. [14].

\section{Results And Discussion}

The first insight is that the current and projected change in electricity demand and profiles contingent to the COVID-19 crisis seems not as significant as to affect future energy supply capacity expansion plans to a great extent. Figure 2 shows the long-term least-cost electricity supply capacity mix under these assumptions, for the Constant Ambition scenario. The trends shown in the figure are representative of those of all scenarios. The supply capacity increases steadily despite the flection in demand. By 2030, the least-cost supply capacity by renewables exceeds the capacity targeted in the PST. Specifically, the capacity of onshore wind turbines and of Concentrating Solar Power just reaches the minimum targets imposed, showing that the two technologies are not competitive under the assumptions of this study; the capacity of solar PV at utility scale overshoots the targets. New capacity of biomass power plants is limited by assumption to $100 \mathrm{MW}$, as from discussions with the local consortium there currently seems to be no plan for further investments. However, if the cap were to be removed and under the current technology assumptions, such capacity could increase much more.

The capacity of natural gas remains significant. Significant new capacity (beyond the current plans) of combined cycles for baseload generation and a certain capacity of open cycle gas turbines for peak load generation are installed.

A sensitivity analysis is performed, where the economic recovery is assumed to be slower and, as a consequence, the increase in electricity demand as well: instead of reaching pre-pandemic values right by 2021 , the demand is assumed to recover by 2023. This does not bring significant changes in the long-term supply capacity trends, except that investments in renewables are slightly delayed. The PST targets are still overshot.

The second insight is that the investments prioritising new low-carbon technologies and security of supply are potentially hindered by high upfront capital costs but are competitive in terms of operation costs and use of resources. In the Increased Ambition scenario, off-shore wind results not cost-competitive in terms of capital 
costs. However, if the investment is assumed as given, the low operation costs and the absence of fuel costs make the project a competitive solution for baseload generation, up to its supply potential (Figure 3). On the contrary, batteries result not cost-competitive, nor necessary under any condition. Both CCGTs and OCGTs are present with enough capacity to provide the reserve needed with increasing shares of variable renewables. However, the role of batteries and the frequency response of the system in these conditions need to be analysed in more detail with higher resolution models. It is to be noted in Figure 2 that natural gas accounts for the largest share in electricity generation, in this scenario like in all others. A non-negligible share of the needs is also covered by energy efficiency measures (light green area) and off-grid generation (both through solar panels and small wind turbines).

In the Prioritising Supply Security scenario, both the new interconnection with Italy and the regasification infrastructure take an important role in the energy supply. Figure 4 shows electricity imports from Italy to become key in the country's supply as soon as the interconnection becomes operational in 2027 . Electricity exports become competitive only above a certain sale price threshold (i.e. around 5.4 USD cents/kWh, according to a sensitivity analysis) and considering high availability of the line. If allowed to an extent sufficient to meet the domestic demand, LNG replaces almost entirely the supply of domestic and imported natural gas.

The third significant insight is that, under the assumptions of this study, the reduction in gas prices caused by the pandemic does not have significant effects on the competitiveness of renewable generation versus gas generation. We performed a sensitivity analysis over the Constant Ambition scenario, assuming more pessimistic projections for gas prices, i.e. halving of gas prices in 2020 and a slower recovery. The halving is meant to reflect projections by the International Energy Agency, which indicate that under the pandemic some oil-indexed gas prices could fall by half over 2020 [15]. The slower recovery assumes that gas prices on average reach pre-pandemic levels only by 2030 . Under these assumptions, solar PV investments still overshoot the PST targets and vary marginally, compared to the Constant Ambition scenario.

The final insight is that in all scenarios the expected contribution of low-carbon solutions (both investments in renewables and energy efficiency) towards job creation is high. Under the assumptions of the Input-Output model used for this analysis, the effects of the COVID-19 pandemic lead to net job losses in the short- to medium-term across the whole Tunisian economy in all scenarios. This seems to be highly dependent on the local content of the investments in new - gas or renewable - technologies, which is assumed to be on average very low in all cases. The job losses are lowest in the Increased Ambition scenario, which differs substantially from the others in that it assumes higher local content for all new investments. In general, investments in new gas infrastructure would cause net job losses, whereas investments in energy efficiency and renewables would cause net job creation, but not as high as to fully counterbalance the losses brought about due to the pandemic.

Interesting insights come from comparing the cumulative difference in jobs created in the period 2020-2040 between the above scenarios and a baseline. We assume as baseline a so-called 'Frozen Future' scenario, where only the currently committed investments and decommissioning projects are accounted for. Besides those, any future increase in demand is assumed to be met by increased generation of natural gas fired power plants. 
In all cases but one, there is net job creation annually, compared to the Frozen Future scenario, due to the higher penetration of renewable technologies and energy efficiency. We show in Figure 5a cumulative job gains relative to the Frozen Future scenario from 2020 to 2030 (due to the assumption of a static economy implicit in the IO model, a more long-term perspective provides no meaningful results). Given the limitations of the multiplier approach, these results should be viewed with caution - multipliers only ever show as a snapshot of the national economy and may not provide a full picture, causing potential overestimation or underestimation of job creation. Yet, the figures indicate rather robust trends that can be expected with energy technology investments. The difference in cumulative job gains between the Increased Ambition (highest growth scenario) and the Frozen Future scenario is highest and around $+63,700$, especially due to the assumption of higher local content of investments, compared to the other scenarios. This shows a positive effect of investments in the energy efficiency and renewable energy value chains on job creation. The positive effects are also found in previous studies, even if built upon different model infrastructure and assumptions [16]. The scenario with second highest job creation (and lowest emissions, as per Figure 5b) is the Prioritising Supply Security scenario. However, for this it must be taken into account that a large share of domestic electricity generation is replaced by imports from 2027 on and this may cause additional job losses not accounted for. Furthermore, the $\mathrm{CO}_{2}$ content of the imported electricity should be considered.

\section{Policy-relevant Insights}

In this work we analysed potential long-term implications of the COVID-19 pandemic on the development of the electricity sector of Tunisia and related job creation, with an energy-economy model. We looked at four main scenarios, depicting different ways the future may play out in terms of electricity demand, international fuel prices and policy and investment priorities. The scenarios were co-designed with a consortium of Tunisian institutions and populated mostly with locally available data. The data is openly available (partially aggregated where confidential) and appended to this study. Parametric analyses were run around these scenarios, to confirm the validity of the conclusions or complement them. Although dependent on the sets of assumptions we used, two main robust insights seem to emerge, for attention of policy makers:

- Solar photovoltaic emerges as a highly competitive solution in the context and its competitiveness seems not significantly affected by the sharp decreases in gas prices contingent to the COVID-19 pandemic.

- The contribution of investments in renewables and energy efficiency measures towards job creation is high, though highly dependent on the local content of the investments. This makes an ambitious expansion of renewable energies and energy efficiency and their value chains potentially an attractive option for the design of economic stimulus packages for a green recovery.

If the country's objectives are to foster decarbonisation while creating jobs, a policy priority may aim to support the local production and construction of renewable technologies. In the case of solar PV particularly, this would also correspond to a highly cost-competitive solution, at assumed costs. Studies dated late 2020 suggest that the local content of investments in renewables may currently lie between $20 \%$ and $40 \%$ (in the range of the Increased Ambition scenario). Under this scenario, job creation is greatest. If greater parts of the value chains were to be concentrated in Tunisia, the effect could be increased. 
Finally, another area worth exploring would be the type of energy efficiency measures to be pushed. Other preliminary analysis suggests that fast payback options may bring in the short term benefits in terms of job creation even if implemented with imported goods.

All these aspects can be easily analysed, as the energy-economy modelling framework used for the analysis is open source and meant for continuous improvement. It has been co-developed and transferred to the local institutions. Aspects requiring immediate attention for improving the electricity system analysis would be: reassessment of the potential of biomass in the electricity mix and refining of the data base for batteries and other storage solutions. It is important to note that the job creation results depend significantly on assumptions such as average wages, wage share of value added and local content. Further, this use of an 10 model is subject to the limitations well discussed in literature (e.g. by Rocco et al. [17]). These limitations and potential improvements of the methodology are pointed out in the Methods papers linked to this work.

\section{Abbreviations}

IO Input-Output

PST Tunisian Solar Plan (Plan Solaire Tunisien)

\section{Declarations}

\section{Data availability}

The data supporting this analysis is openly available under license CC BY 4.0 (https://creativecommons.org/licenses/by/4.0/) and annexed to this publication.

\section{Author contributions}

Francesco Gardumi: conceptualisation, methodology, data curation, visualisation, investigation, original draft preparation; Nesrine Mhiri: data curation, investigation; Mark Howells: methodology; Franziska Bock: data curation, review, editing; Thameur Necibi: data curation, review; Chiheb Bouden: review.

\section{Acknowledgements}

This work has been produced in the scope of a project implemented by Deutsche Gesellschaft für Internationale Zusammenarbeit (GIZ) GmbH. Responsibility for the contents of this paper lies entirely with the authors and can in no way be taken to reflect the views of GIZ.

Mark Howells acknowledges the support of the Climate Compatible Growth Program (\#CCG) of the UK's Foreign Development and Commonwealth Office (FCDO). The views expressed in this paper do not necessarily reflect the UK government's official policies.

\section{Conflicts of interest}

The authors declare no conflict of interest. 


\section{References}

[1] OECD, "COVID-19 crisis response in MENA countries," Jun. 2020. Accessed: Aug. 21, 2020. [Online]. Available: https://read.oecd-ilibrary.org/view/?ref=129_129919-4li7bq8asv\&title=COVID-19-Crisis-Response-inMENA-Countries.

[2] The World Bank, "Coping with a Dual Shock: COVID-19 and Oil Prices," Apr. 14, 2020.

https://www.worldbank.org/en/region/mena/brief/coping-with-a-dual-shock-coronavirus-covid-19-and-oilprices (accessed Aug. 21, 2020).

[3] The Conversation, "Oil price: futures markets warn it won't recover after coronavirus," Apr. 30, 2020.

[4] Ministère de l'Energie, des Mines et de la Transition Energétique and Observatoire National de l'Energie et des Mines, "Conjoncture Énergétique - Rapport mensuel, fin mai 2020," Republique Tunisienne, Tunis, Tunisia. Accessed: Aug. 21, 2020. [Online]. Available: http://data.industrie.gov.tn/wp-content/uploads/Conjonctureenergetique-mai-20201.pdf.

[5] A. Nouicer and A. Dhakouani, "The Tunisian power system and the COVID-19 pandemic," May 12, 2020.

[6] F. Carril Caccia, J. Milgram Baleix, and J. Paniagua, "FDI in the MENA Region: Factors that Hinder or Favour Investments in the Region," in IE Med. Mediterranean Yearbook 2018, European Institute of the Mediiterranean, 2018.

[7] M. Howells et al., "OSeMOSYS: The Open Source Energy Modeling System: An introduction to its ethos, structure and development," Energy Policy, vol. 39, no. 10, pp. 5850-5870, Oct. 2011, doi:

10.1016/J.ENPOL.2011.06.033.

[8] M. I. Howells and S. Laitner, "Industrial efficiency as an economic development strategy for South Africa," presented at the International Energy Workshop, Paris, France, Jul. 2004, Accessed: Mar. 27, 2020. [Online]. Available: https://www.africaportal.org/publications/industrial-efficiency-as-an-economic-developmentstrategy-for-south-africa/.

[9] H. Winkler, M. Howells, and K. Baumert, "Sustainable development policies and measures: institutional issues and electrical efficiency in South Africa," Clim. Policy, vol. 7, no. 3, pp. 212-229, 2007.

[10] OECD, “National Input-Output Tables," 2018.

https://stats.oecd.org/OECDStat_Metadata/ShowMetadata.ashx?

Dataset=IOTSI4_2018\&ShowOnWeb=true\&Lang=en (accessed Nov. 19, 2020).

[11] A. Dhakouani, F. Gardumi, E. Znouda, C. Bouden, and M. Howells, "Long-term optimisation model of the Tunisian power system,” Energy, vol. 141, pp. 550-562, Dec. 2017, doi: 10.1016/j.energy.2017.09.093.

[12] A. Dhakouani, E. Znouda, and C. Bouden, "Impacts of energy efficiency policies on the integration of renewable energy," Energy Policy, vol. 133, p. 110922, Oct. 2019, doi: 10.1016/j.enpol.2019.110922. 
[13] Agence Nationale pur la Maitrise de l'Energie, "Plan Solaire Tunisien: Programmation, conditions et moyens de la mise en oevre," Tunis, Tunisia, Apr. 2012. Accessed: Apr. 01, 2020. [Online]. Available: http://www.anme.nat.tn/fileadmin/user1/doc/DEP/Rapport_final_PST.pdf.

[14] I. Pappis et al., "Conflicting objectives of energy development and water security in Africa," 2020.

[15] International Energy Agency, “Gas 2020,” IEA, Paris, France, Jun. 2020. Accessed: Dec. 22, 2020. [Online]. Available: https://www.iea.org/reports/gas-2020.

[16] GIZ and ANME, "Renewable energy and energy efficiency in Tunisia - employment, qualification and economic effects," Deutsche Gesellschaft für Internationale Zusammenarbeit (GIZ) GmbH, 2012. Accessed: Apr. 07, 2020. [Online]. Available: https://energypedia.info/images/8/85/EN_Renewable_energy_and_energy_efficiency_in_Tunisia_GIZ_2012.pdf.

[17] M. V. Rocco, F. Tonini, E. M. Fumagalli, and E. Colombo, "Electrification pathways for Tanzania: Implications for the economy and the environment," J. Clean. Prod., vol. 263, p. 121278, Aug. 2020, doi: 10.1016/j.jclepro.2020.121278.

\section{Figures}




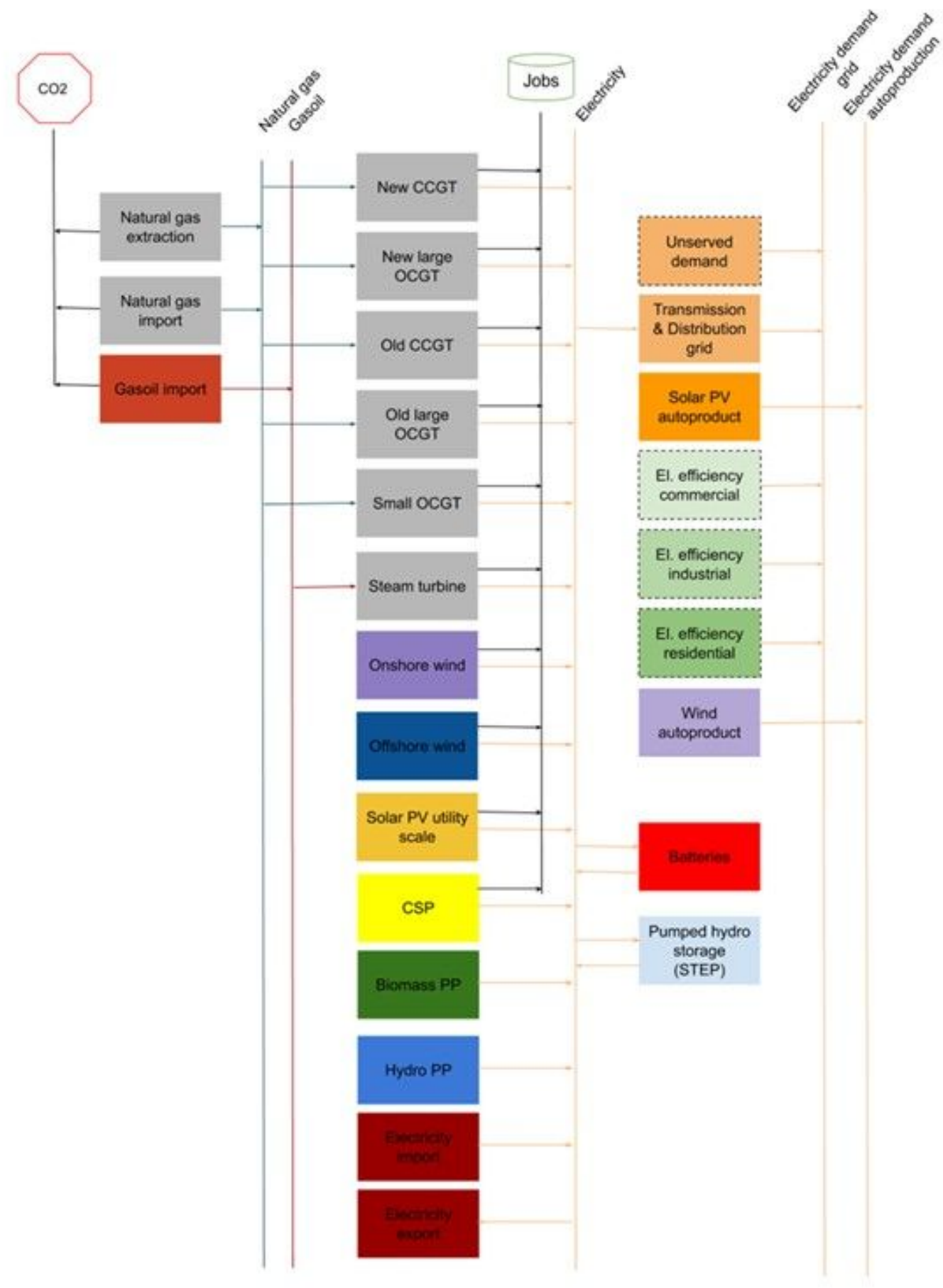

Figure 1

Schematic representation of the electricity system of Tunisia, as included in the model. 


\section{Constant Ambition}

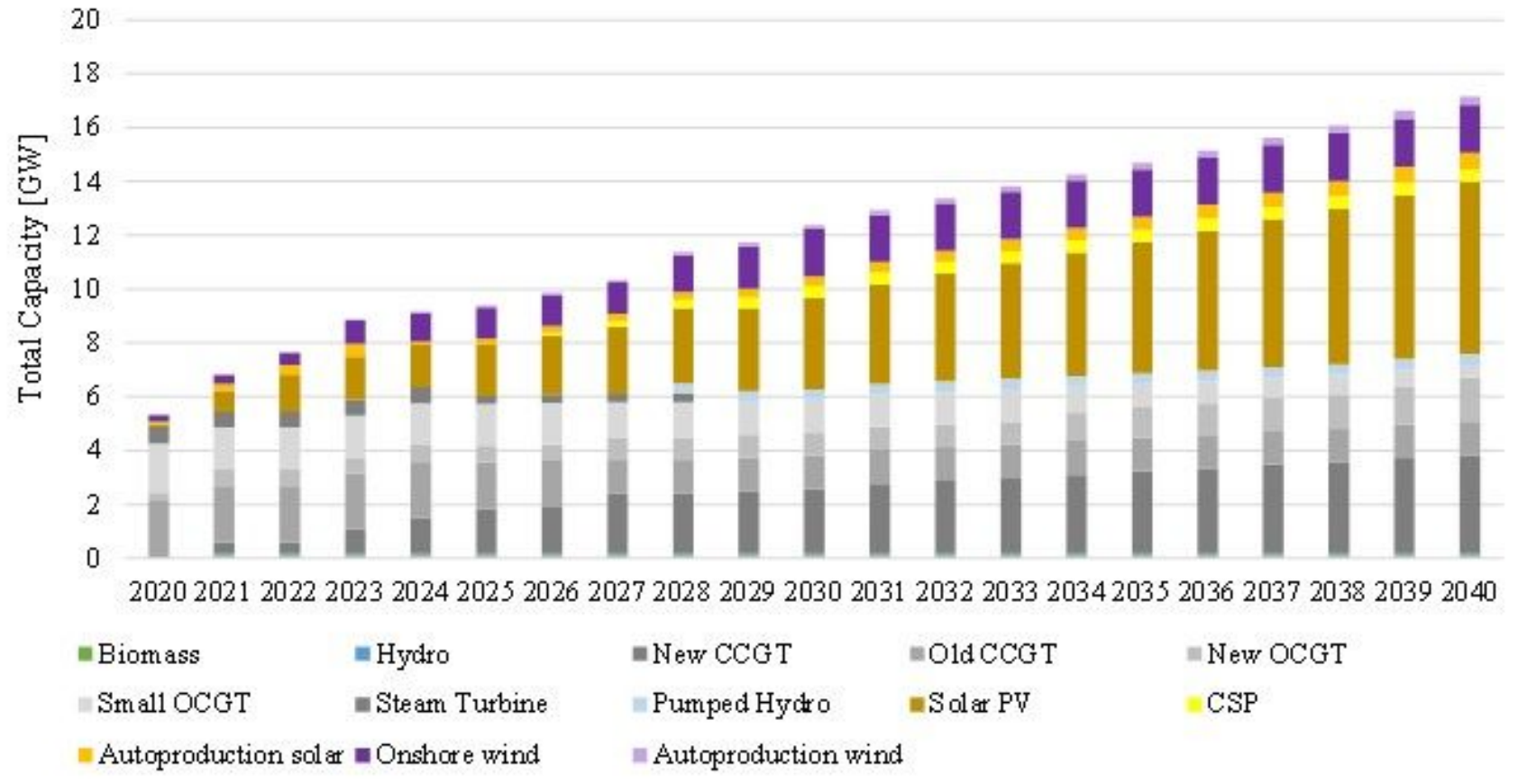

Figure 2

Installed power supply capacity in the Constant Ambition scenario.

\section{Increased Ambition}

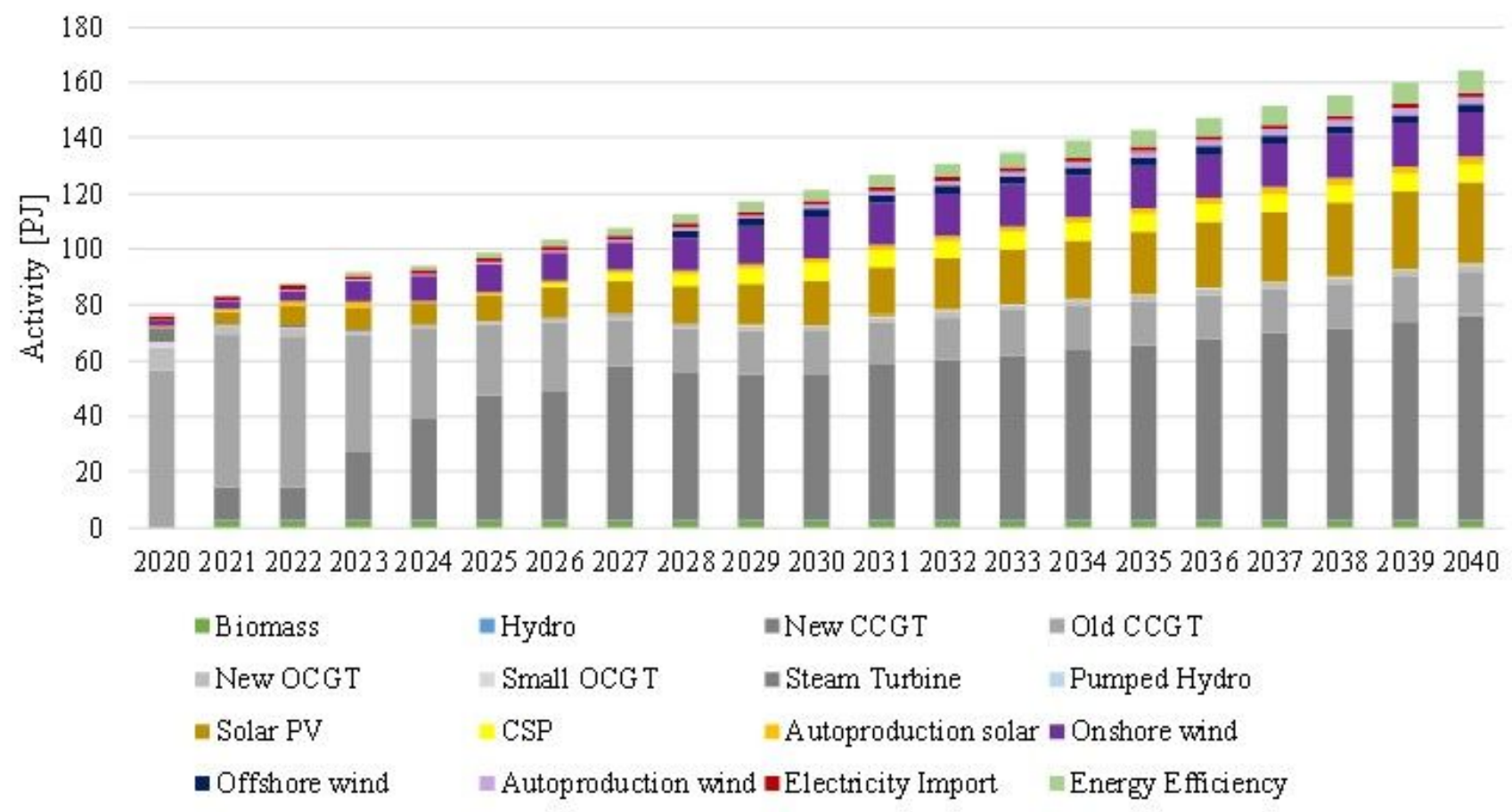

Figure 3 
Electricity supply in the Increased Ambition scenario.

\section{Prioritising Supply Security}

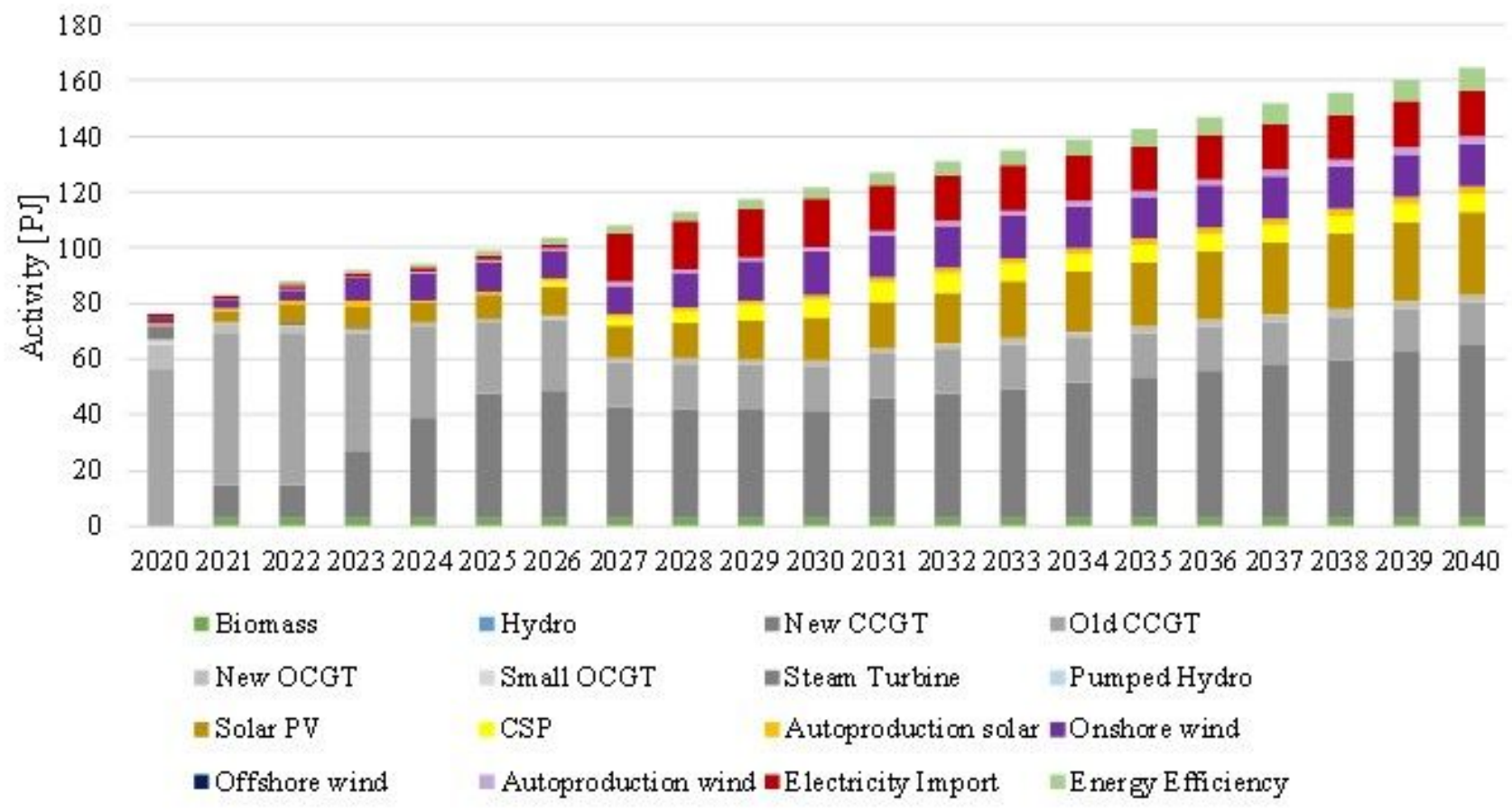

Figure 4

Electricity supply in the Prioritising Supply Security scenario.

a)

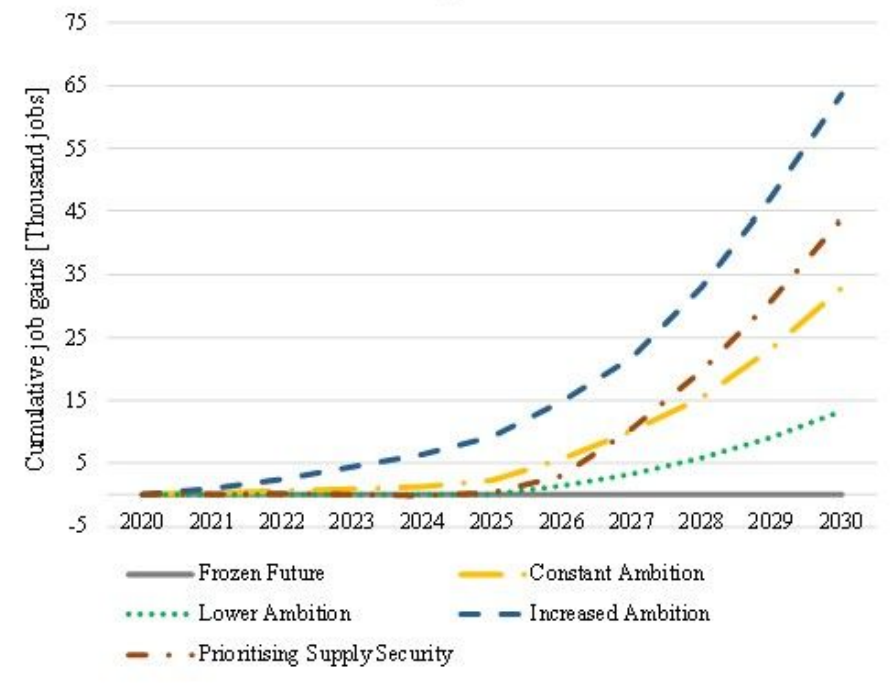

b)

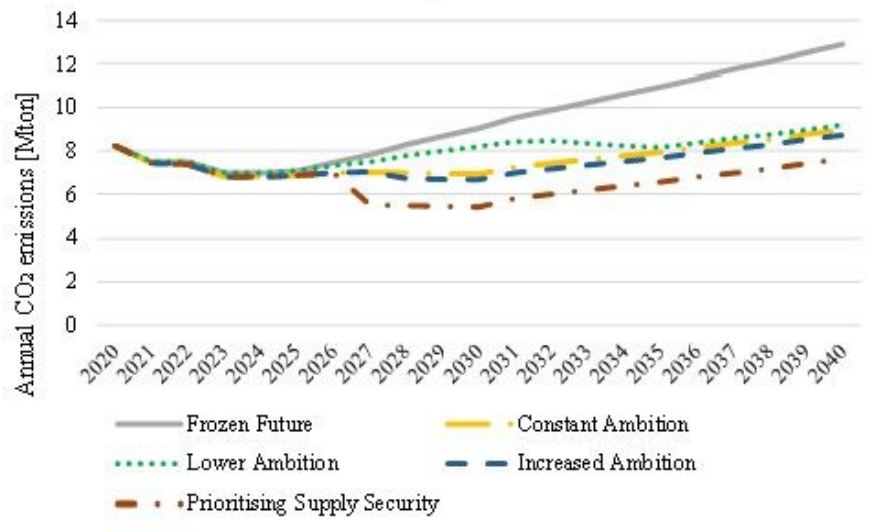

\section{Figure 5}

a) Cumulative job gains by scenario; b) Annual CO2 emissions by scenario. 